John Bitchener, Neomy Storch, Rosemary Wette (Eds), Teaching Writing for Academic Purposes to Multilingual Students - Instructional Approaches

New York: Routledge

\title{
Catherine Colin
}

\section{(2) OpenEdition}

\section{Journals}

Electronic version

URL: http://journals.openedition.org/asp/6413

DOI: $10.4000 /$ asp. 6413

ISSN: 2108-6354

\section{Publisher}

Groupe d'étude et de recherche en anglais de spécialité

\section{Printed version}

Date of publication: 1 November 2020

Number of pages: 145-150

ISSN: 1246-8185

\section{Electronic reference}

Catherine Colin, "John Bitchener, Neomy Storch, Rosemary Wette (Eds), Teaching Writing for Academic Purposes to Multilingual Students - Instructional Approaches", ASp [Online], 78| 2020, Online since 01 November 2020, connection on 06 March 2021. URL: http://journals.openedition.org/asp/6413 ; DOI: https://doi.org/10.4000/asp.6413

This text was automatically generated on 6 March 2021

Tous droits réservés 


\section{John Bitchener, Neomy Storch, Rosemary Wette (Eds), Teaching Writing for Academic Purposes to Multilingual Students - Instructional Approaches}

New York: Routledge

Catherine Colin

\section{REFERENCES}

Bitchener, John, Neomy Storch \& Rosemary Wette (Eds). 2017. Teaching Writing for Academic Purposes to Multilingual Students - Instructional Approaches. ESL \& Applied Linguistics Professional Series. New York: Routledge, 220 pp. ISBN: 978-1-1382-8421-0. 
1 When teaching academic writing to international students, instructors in search of helpful resources may sometimes be under the impression that there are broadly two kinds of books available to help them besides general textbooks on writing research: theoretical, research-based ESP approaches, on the one hand, and practical, hands-on ESL books providing specific vocabulary or grammar exercises, on the other.

2 Teaching Writing for Academic Purposes to Multilingual Students - Instructional Approaches offers an interesting middle ground between these by "bridging together theory and practice", a phrase used in the subtitle of Chapter 2 that aptly describes the ambition of this collection of

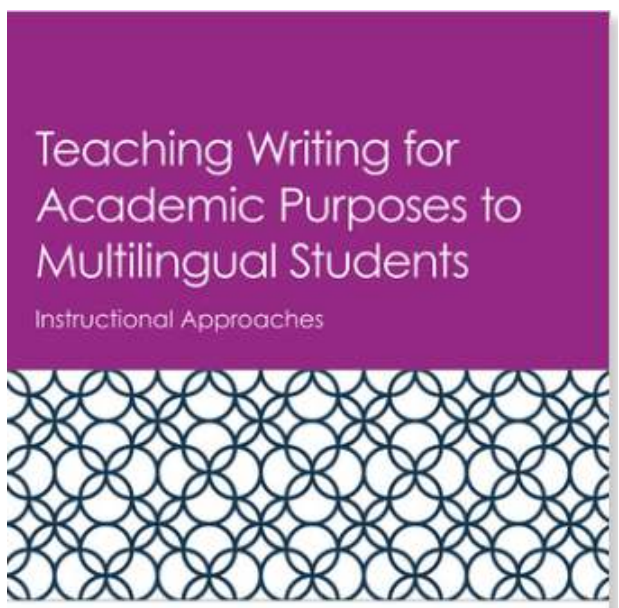

Edited by John Bitchener, Neomy Storch, and Rosemary Wette

ESL \& APPLIED LINGUISTICS PROFESSIONAL SERIES thirteen chapters all focusing on EAP instruction in different contexts across the world. Based on the premise that the demand for EAP writing courses has soared in many different countries, especially among non-native speakers of English (Hamp-Lyons 2011; Ding 2019), this book explicitly aims to provide examples of concrete pedagogical approaches that have been implemented in the classroom by experienced researchers and instructors. The book is divided into three parts: EAP courses in university degree programs, instruction in specific EAP knowledge and skills, and future research and scholarship in EAP.

The intent of the editors was threefold, as explained in the introduction (Chapter 1). Firstly, they sought to provide a collection of articles that would illustrate the variety and diversity of institutional and socio-cultural contexts in which EAP instruction is offered. Secondly, since the book is explicitly anchored in practice, the editors explain how it is meant to appeal to a large audience, from graduate students to more seasoned instructors. Thirdly, they highlight one of the strengths of the book - its intentional focus on the link between theory and practice. Summaries of each chapter are also included.

4 Part I provides several examples of how EAP courses have been developed and implemented in different academic contexts.

5 In Chapter 2, "Context and the teaching of academic writing", Brian Paltridge describes three different EAP writing courses at various levels. His approach hinges on developing students' awareness not only about text but also about the context of academic genres, helping students understand the "socially situated nature of texts" (p.11), given that successful, effective writing implies meeting (sometimes tacit) institutional or disciplinary expectations. In all three courses that are described in this chapter, the author encourages students to develop a keener understanding of academic literacy by reflecting critically on literacy expectations as readers or as writers in their disciplines, based on tasks that have been carried out in their classes. This chapter will certainly be valuable to many EAP writing teachers who may be aware 
of the existence of disciplinary conventions, but may feel at a loss or overwhelmed when having to teach multidisciplinary groups of students.

The importance of disciplinary context in teaching academic writing is also highlighted in Ken Hyland's "Learning to write for academic purposes", in which he describes how the undergraduate EAP curriculum at the University of Hong Kong (HKU) was reformed. As in Paltridge's chapter, the key idea here is to ensure students and instructors understand there is more to writing than just language proficiency - it is about acquiring a new kind of literacy, which is discipline-dependent. The reform at HKU led to the creation of two English courses, one in general EAP (Core University English) and another, more disciplinary-specific (English in the Discipline), in order to acknowledge the need for a more "discipline-sensitive approach to English" compared to courses that focus only on more general academic writing skills. To illustrate such need for specificity in EAP courses, Hyland reviews recent research to show how discipline influences academic genres. Hyland concludes his article by providing a concrete example of how an "English in the discipline" course was designed at HKU, English for Clinical Pharmacy. By doing so, he also reminds the reader of a paramount factor in designing a more discipline-specific EAP course or ESP courses in general: the necessity for collaboration between EAP teachers and faculty of other disciplines. Overall, this chapter makes a strong case for a more discipline-sensitive approach in EAP course design. The example that Hyland provides perfectly illustrates what most ESP teachers would like to achieve: a course jointly designed by EAP instructors and faculty from the students' own disciplines, which successfully blends language learning and disciplinary content, and provides students with authentic communicative tasks that mirror their future professional practice.

7 Another example of course design is provided in Chapter 4, "Developing a flexible, insessional EAP writing program for undergraduates at a large research university in the United States". In this chapter, Tony Silva explains the manner in which he developed an undergraduate writing program at Purdue University over the course of 25 years, based on sequenced writing. Course documents are provided as appendices and include course policies, class schedule, description of all class assignments and evaluation forms. These documents allow the reader to form a very precise idea of how the course was designed and implemented, and they could easily be used to illustrate the process of curriculum design to teacher trainees or graduate students in language teaching.

Part II more narrowly focuses on skills and activities in EAP writing.

9 Genre-based pedagogies have underpinned curriculum design in EAP courses in recent decades, following Swales' (1990) seminal work on academic genre. Although this approach is common, little work has been carried out to assess how it is used by novice teachers and whether they experience any challenges in implementing it. It is precisely this question that Christine M. Tardy sets out to address in "The challenge of genre in the academic writing classroom," by following six teachers who integrated genre into their EAP courses over two semesters. These teachers faced several challenges including uncertainty over the students' understanding of the very concept of genre and the exact purpose of the class, or over the students' ability to transfer their knowledge to other courses. Interestingly, they also struggled with focusing more explicitly on language. Drawing on these results, Tardy proposes four avenues for improving L2 teacher training: offering an introduction to genre theories, exploring multiple pedagogical approaches based on genre, providing tools for linguistic analysis, 
and encouraging explicit reflection on teachers' goals and practices. While Tardy's observations primarily focus on early undergraduate writing programs in the US, they are relevant on a larger scale as they highlight a recurring concern in ESP practices around the world, namely teacher education and training.

10 John Bitchener's contribution allows the reader to zoom in and focus on a specific feature of academic writing - the argument - and the difficulties student L1 or L2 writers encounter in forming them. To help students cope with a task that requires a set of complex skills, especially for L2 students (adapting to a different epistemological background, knowing how to read and understand academic texts, developing critical judgment and one's linguistic repertoire), Bitchener proposes a seven-stage model intended to scaffold students through the process of writing effective arguments for a literature review. This approach, relying on diagrammatic representations of the writer's thought processes, aims to guide students more explicitly, from reading and understanding the literature to actually writing up one or several units of the literature review. By breaking down the very process and methodology for writing an argument, Bitchener's sound scaffolding strategies echo other contributions in the book in demonstrating that the teaching of EAP is not just about language proficiency but about developing skills related to a new kind of literacy.

11 Rosemary Wette's chapter also touches on a specific feature of writing that students often struggle with which is how to cite and use sources. In "L2 Undergraduate students learning to write using sources," Rosemary Wette reminds the reader that plagiarism is far from being a straightforward concept considering the collaborative and intertextual nature of academic texts. Knowing how to use sources is therefore considered here as a "complex, multi-faceted, academic literacy skill set with a number of technical, linguistic, rhetorical, disciplinary and cultural elements" (p. 101), which will echo Bitchener's considerations on argument writing in the previous chapter. Based on an overview of recent research on the subject, she outlines the skills necessary to use sources effectively and proposes a "trajectory of skill development" that summarizes the key phases of L2 development in mastering that precise skill, from novice to proficient writer. Of particular relevance to instructors, she also shows how her model can be applied in the classroom by providing two outlines for course content depending on the students' proficiency level (novice or intermediate), and by offering suggestions for instructional tasks and activities.

12 While a number of contributions in the book have highlighted the role of reading in learning academic writing, Jennifer Hammond's chapter examines the role of oral interaction in the development of writing skills. She deals with "literate talk" in Chapter 8; a term referring to "the nature of talk that introduces educational concepts to students, and provides discipline-specific ways of talking about those concepts" (p. 116). She describes how literate talk was used in a Year 6 Science Program in Australia with L2 learners and explains how tasks and the language required to carry them out were located on a continuum from "most spoken" to "most written." "Literate talk" is therefore seen here as a stepping stone helping students consolidate their understanding of scientific concepts and honing their linguistic skills before carrying out the final task consisting in formulating a piece of independent scientific writing. While this approach seems to be beneficial to L2 students, achieving a full understanding of the concept of "literate talk" may prove challenging to the reader, as unfortunately no concrete examples of class interaction where it would be at play are 
given. The link between oral and writing skills and the idea of a continuum from "most spoken" to "most written" does, however, contribute to a better understanding of the role classroom interaction plays in scaffolding writing skills.

13 Neomy Storch looks at another kind of interaction in Chapter 9, and deals with the benefits of collaborative writing in EAP classes. Her review of current research on the subject is consistently followed by practical accounts of her own experience, which allows the reader to comprehend fully the links between theory and practice. Her thorough and clear explanations will help the reader make informed decisions regarding choosing task types (meaning focused vs language-focused collaborative tasks and their influence on L2 learning), grouping learners (by size, proficiency levels, teacher allocation or self-selection) and assessing collaborative writing. This chapter can be considered as a good resource for pre-service training or for instructors who wish to implement more collaborative writing but may not know where to start.

The next two chapters complement the previous approaches as they focus on language development and more precisely error treatment in developing EAP writing skills.

Chapter 10, "Facilitating L2 writers' academic language development", Dana Ferris focuses on helping L2 learners to be proactive when developing their language skills instead of reacting to error feedback. Perhaps surprisingly for those accustomed to L2 settings only, she gives a reminder that working on language skills when teaching EAP is sometimes overlooked due to lack of proper teacher training, especially if instructors are trained for L1 settings. In this chapter, she shows how explicit focus on form can be authentically integrated into course content, with numerous examples of class activities based on her own practice that will provide students not only with content, but also strategies to develop their metalinguistic awareness and improve their writing skills autonomously.

Icy Lee's chapter, entitled "Working hard or working smart," provides an overview of current research on corrective feedback and addresses a well-known concern among language teachers: Should instructors correct all mistakes (i.e. give comprehensive feedback) or should they resort to focused feedback, where only specific error types are targeted? While it seems established that focused feedback has more benefits for learners, the stakes are high in terms of accuracy when it comes to academic writing, and thus the answer may not be as straightforward as it seems. Instead, she calls for a combined approach that would mix both comprehensive and focused feedback, and gives precise examples on how it can be implemented. One particularly interesting suggestion is that of using error ratio analysis sheets, which would assist students in developing a clearer picture of their strengths and weaknesses.

17 Part III is devoted to discussing future research in EAP and comprises a single chapter by Rosa M. Manchón, "The multifaceted and situated nature of the interaction between language and writing in academic settings: advancing research agenda." Her overview of recent research trends draws our attention to the relation between language processing and language development, that is to say, how the process of writing actually interacts with and affects language learning. Investigating the factors such as identity or ideology that influence linguistic choices in different settings is also proposed as another avenue for future research.

18 Finally, in her concluding epilogue, Christine Pearson Casanave summarizes the common themes that underpin the book as a whole, and provides a synthetic view of how all contributions link together - from the call for explicit instruction that fits local 
needs, the focus on steps or trajectories that scaffold the writing process, to the challenges faced by teachers, among other topics.

19 A key strength of this book is its constant concern for pedagogy and the consistent application of theoretical insights into concrete pedagogical approaches. This makes this book not only rather pleasant to read but also successful at achieving relevance for a large audience. Graduate students in applied linguistics for instance will certainly find some of the contributions helpful, as some chapters will provide them with up-todate overviews of current issues (e.g. collaborative writing in Chapter 9, or error treatment in Chapter 11). While more experienced researchers or instructors will undoubtably already be familiar with some concepts mentioned in a number of chapters (e.g. genre theory), they will nevertheless find inspiration in the many stimulating examples of activities or approaches described in the book to aid them in adopting a renewed perspective on their existing EAP courses.

Despite these merits, two minor shortcomings could be underlined. First, it was sometimes unclear how much time was devoted to some of the activities described or for how long some courses ran. It may seem like an unimportant detail, but as Dana Ferris aptly describes in Chapter 10, timing is often an issue for EAP instructors as much content needs to be covered in sometimes as little as 10 or 15 hours in one semester. The reason why it matters is feasibility and transferability: providing greater detail would have allowed the reader to better realize whether the described approaches could be easily implemented in their own contexts.

Secondly, although the editors obviously could not have foreseen a global pandemic when the book was published, writing this review in 2020 draws one's attention to the fact that there were very few references to online tools and none to online teaching. An example of how to build an entire EAP course online would have been a welcome addition that could have easily been included in Part I and would have resonated perfectly with the overall purpose of the book, with "online" being understood as another form of context and place.

Overall, this book is successful at meeting its primary objective - giving several examples of different instructional approaches to EAP in different contexts - but it is also valuable in that it provides many different synthetic overviews of recent research issues related to EAP teaching and their applications in the classroom. It is also successful at showing the complex, multifaceted nature of academic writing, and a good reminder of the highly dynamic processes at play involving a range of subskills that should not be overlooked (reading, critical thinking, rhetoric, discipline expectations, to cite but a few examples), be it in L1 or L2 settings. In sum, all the contributions provide a sound demonstration for one of the common themes underpinning the volume: a call for robust, specialized teacher training that would allow instructors to design and conduct their EAP classes confidently. 


\section{BIBLIOGRAPHY}

DING, Alex. 2019. "EAP Practitioner Identity”, in HYLAND, K. \& E. wONG (Eds.), Specialised English. New directions in ESP and EAP Research and Practice. New York: Routledge, 62-73.

HAMP-LYONS, Liz. 2011. "English for academic purposes", in HINKEL, E. (Ed.), Handbook of Research in Second Language Teaching and Learning, Vol. II. New York: Routledge, 89-105.

SWALES, John. 1990. Genre Analysis: English in academic and research settings. Cambridge: Cambridge University Press.

\section{AUTHORS}

\section{CATHERINE COLIN}

ENS Paris-Saclay, catherine.colin@ens-paris-saclay.fr 